\title{
Superiority index based on AMMI and yield of wheat genotypes evaluated in North Western Plains Zone under restricted irrigated timely sown conditions
}

\author{
Ajay Verma* and G. P. Singh \\ ICAR-Indian Institute of Wheat and Barley Research, Karnal (Haryana) India \\ (Email: ajay.verma1@icar.gov.in)
}

\begin{abstract}
Highly significant effects of environment (E), GxE interaction and genotypes (G) were observed by AMMI analysis during 2018-19 and 2019-20 study years for wheat genotypes evaluated at major locations of mega zone of the country. WAASB measure observed suitability of HD3237, WH1080 and PBW644 genotypes. Superiority index while weighting 0.65 and 0.35 for yield and stability found HI1620, HD3237 and HI1628 as of stable performance with high yield. PRVG measure observed suitability of HI1620, HI1628 and BRW3806 while MHPRVG measure identified HI1620, HI1628 and HD3237 wheat genotypes. More over the average yield of genotypes ranked HI1620, HI1628 and NIAW3170 as of order of choice. SI had expressed all direct relations of moderate to high degree of correlations except with WAASB and weak relations with yield, PRVG and MHPRVG values. Only negative correlations had expressed by WAASB measure while positively correlated with yield, PRVG and MHPRVG. Second year of study observed suitability of NIAW3170, DBW296 and PBW644 genotypes as far as WAASB values were concerned. Superiority index found DBW296, HUW838 and NIAW3170 as of stable performance with high yield. More over the average yield of genotypes ranked DBW296, HUW838 and JAUW672 as of order of choice. Mean yield showed a highly significant positive correlation with SI, MHPRVG, PRVG and negative values of correlation with AMMI based measures. SI had expressed all inverse relations with measures WAASB, EV, ASV, MASV as only negative values were seen. Positive correlations were maintained by WAASB measure with Za, SIPC, ASTAB, ASV1.
\end{abstract}

Key Words : AMMI analysis, ASV, SIPC, Za, EV, SI, SSI, Biplot graphs

View Point Article : Verma, Ajay and Singh, G.P. (2021). Superiority index based on AMMI and yield of wheat genotypes evaluated in North Western Plains Zone under restricted irrigated timely sown conditions. Internat. J. agric. Sci., 17 (1) : 73-82, DOI:10.15740/HAS/ IJAS/17.1/73-82. Copyright@2021: Hind Agri-Horticultural Society.

Article History : Received : 22.10.2020; Revised : 17.11.2020; Accepted : 19.12.2020

\footnotetext{
* Author for correspondence :
} 